\title{
ANÁLISE INTEGRADA DO AMBIENTE: UM ESTUDO DE CASO NA BACIA HIDROGRÁFICA DO RIBEIRÃO GERIVA, BRASILÂNDIA/MS
}

\author{
Angélica Estigarribia São Miguel ${ }^{1}$
}

Rafael Brugnolli Medeiros ${ }^{2}$

Wallace de Oliveira ${ }^{3}$

\begin{abstract}
RESUMO
Sendo a bacia hidrográfica um ambiente que existem diversos elementos onde todos são correlacionados, sua análise integrada é necessária, permitindo que tenha um conhecimento da evolução dos futuros cenários. O presente trabalho tem como objetivo elaborar uma análise integrada do ambiente, com ênfase no meio físico da Bacia Hidrográfica do Ribeirão Geriva, que fica localizada no município de Brasilândia em Mato Grosso do Sul. Para a elaboração da pesquisa foi feitos mapeamentos de geologia, solos, declividade, hipsometria, perfis topográficos (longitudinal e transversal do alto, médio e baixo curso), hierarquia fluvial e uso e ocupação da terra do mês de março de 2014. Para o mapeamento foram utilizadas imagens do satélite Landsat 8 processadas com o auxilio do software ArcGis. Como resultados, observa-se que na bacia predominam relevo aplainado recobertos por latossolo vermelho que se assenta sobre terrenos do grupo Bauru, formação Santo Anastácio. Os mapas hipsométricos, perfis topográficos e declividade, apontaram que existem apenas alguns desníveis acentuados, tanto é que em sua grande maioria foi constatada a classe 0 à $6 \%$ de declividade. Com relação ao uso e ocupação da terra, sua grande maioria foi de pastagens, porém, nota-se um aumento na quantidade de áreas destinadas à silvicultura. Concluiu-se que estudos integrados de determinado ambiente pressupõem o entendimento de sua dinâmica com ou sem interferência do homem, dessa forma, essas análises podem auxiliar em um futuro planejamento para a área.
\end{abstract}

PALAVRAS-CHAVE: Bacia Hidrográfica; Análise Integrada; Meio Físico.

\footnotetext{
${ }^{1}$ Graduada em Geografia e Bolsista CAPES pelo Programa de Pós-graduação em Geografia da UFMS/CPTL; angelica.esm@hotmail.com;

${ }^{2}$ Graduado em Geografia e Bolsista CAPES pelo Programa de Pós-graduação em Geografia da UFMS/CPTL; rafael bmedeiros@hotmail.com;

${ }^{3}$ Professor Doutor Associado II da UFMS/CPTL; wallaceoliveira@hotmail.com;
} 


\title{
INTEGRATED ANALYSIS OF ENVIRONMENT: A CASE STUDY IN THE HYDROGRAPHIC BASIN RIBEIRAO GERIVA, BRASILÂNDIA/MS
}

\begin{abstract}
Being the hydrographic basin an environment where that there several elements all are correlated, its integrated analysis is necessary, allowing to have a knowledge of the evolution of future scenarios. The present study aims to elaborating an integrated analysis environment, with emphasis on the physical environment of the Hydrographic Basin of Ribeirao Geriva, which is located in municipality Brasilandia in Mato Grosso do Sul. For the elaboration of research was made mappings from geology, soils, slope, hypsometry, topographical profiles (longitudinal and transversal the high, middle and low course), fluvial hierarchy and use and occupation of land in the month of March 2014. For the mapping were used satellite images Landsat 8 processed with the aid of ArcGIS 10 software. As a result, it is observed that predominate in the basin planed relief covered by red latosol that sitteth on the Bauru group grounds, formation Santo Anastacio. The hypsometric maps, topographical profiles and slope, pointed out that exist only and some steep drop-offs, both that is in their great majority found was class 0 to $6 \%$ of slope. With relation to the use and occupation of land, their great majority of was pasture, however, it is noted an increase in the quantity of areas destined to the silviculture. It was concluded that integrated studies of certain environment presuppose the understanding of their dynamics with or without human interference, that way, these analyzes may aid in future planning for the area.
\end{abstract}

KEY-WORDS: Hydrographic Basin; Integrated Analysis; Physical Media.

\section{ANÁLISIS INTEGRADO DEL AMBIENTE: UN ESTUDIO DE CASO EN LA CUENCA HIDROGRÁFICA RIBEIRÃO GERIVA, BRASILÂNDIA/MS}

\begin{abstract}
RESUMEN
Siendo la cuenca hidrográfica un ambiente que existen muchos elementos donde todos están correlacionados, su análisis integrado se requiere, permitiéndole tener un conocimiento de la evolución de los escenarios futuros. Los presentes objetivos del estudio desarrollar un análisis integrado del medio ambiente, con énfasis en el entorno físico de la Cuenca Hidrográfica Ribeirão Geriva, que se encuentra en el municipio de Brasilândia en Mato Grosso do Sul. En la elaboración de estudio fue hecho mapeos geología, suelos, pendiente, hipsometría, perfiles topográficos (longitudinal y transversal el superior, medio y el curso inferior), jerarquía fluvial y el uso y ocupación de tierra de marzo de 2014. Para mapeo fueron utilizados imágenes de satélite Landsat 8 procesados con la ayuda del software ArcGIS. Como resultado, se observa que la cuenca predominan relieve aplanado cubierta por latosol rojo que se sienta en terrenos del formación en grupo Bauru, formación Santo Anastacio. Los mapas hipsométricas, perfiles topográficos y de pendiente, señalaron que sólo existen algunas desniveles empinadas, por lo que se encuentran en su mayoría era de clase 0 a $6 \%$ de pendiente. Con relación con el uso y ocupación del tierra, en su mayoría fue pastos, sin embargo, se nota un aumento en la cantidad de áreas para la actividad silviculture. Se concluyó que los estudios integrados de determinado entorno presuponen la entendimiento de su dinámica con o sin la intervención humana, por lo tanto, estos análisis pueden ayudar en la futuro planificación de la area.
\end{abstract}

PALABRAS-CLAVE: Cuenca Hidrográfica; Análisis integrado; Medio Físico. 


\section{INTRODUÇÃO}

A geografia enquanto ciência apresenta categorias consideradas essenciais para a compreensão de seu estudo, dentre elas destaca-se a paisagem e o território. Dessa forma, a paisagem é considerada pela maioria das correntes do pensamento geográfico, um conceito-chave da Geografia, sendo utilizado de diferentes maneiras e por várias ciências.

A bacia hidrográfica é um exemplo da dinâmica e da interação entre os elementos do meio natural e antrópico, dessa forma, cresceu enormemente o seu valor como unidade de análise e planejamento ambiental.

Segundo Santana (2003), a bacia hidrográfica é uma porção geográfica delimitada por divisores de água, englobando toda a área de drenagem de um curso d'água. É uma unidade geográfica natural e seus limites foram estabelecidos pelo escoamento das águas sobre a superfície ao longo do tempo. É, portanto, o resultado da interação da água com outros recursos naturais.

A partir deste sentido de interação entre todos os elementos presentes no ambiente, sua análise integrada é necessária, pois permite que se tenha o conhecimento das possíveis evoluções destes cenários.

Neste sentido Tricart (1977), afirma que os ambientes devem ser estudados pelo seu comportamento dinâmico, ou seja, é necessária uma análise de cada característica de determinado local e suas interações, para que se possa analisar o ambiente como um todo, já integrando os fluxos de energia que entram e saem da natureza a todo instante.

Essa análise integrada dos elementos físicos do ambiente foi feita sobre a Bacia Hidrográfica do Ribeirão Geriva - BHRG possuindo uma característica particular, que é contribuição antrópica para a mudança do ambiente, pois vem ocorrendo o cultivo de eucalipto pertencente à Fibria-MS Celulose Sul MatoGrossense Ltda; onde este estudo permite contribuir para um melhor ordenamento e gerenciamento da bacia, podendo servir de planejamento para prevenir eventuais impactos causados por este tipo de ocupação na paisagem e nos recursos hídricos. 
Dessa forma, o objetivo principal desta pesquisa será analisar integralmente o ambiente em questão, levando em consideração os elementos físicos da bacia, através de diversas variáveis como geologia, solos, declividade, hipsometria, perfis topográficos (longitudinal e transversal do alto, médio e baixo curso), hierarquia fluvial e uso e ocupação da terra.

A BHRG é afluente da margem direita do Rio Verde, que por sua vez, deságua no Rio Paraná, ocupa uma área de $359,29 \mathrm{~km}^{2}$, localizada entre as coordenadas geográficas $52^{\circ} 28^{\prime} 0$ " W e $52^{\circ} 16^{\prime} 0$ " W a $21^{\circ} 12^{\prime} 0^{\prime \prime} \mathrm{S}$ e $21^{\circ} 00^{\prime} 0$ " S, conforme mostra a Figura 1.

Figura 1: Localização e Articulação da Bacia Hidrográfica do Ribeirão Geriva, Brasilândia/MS.

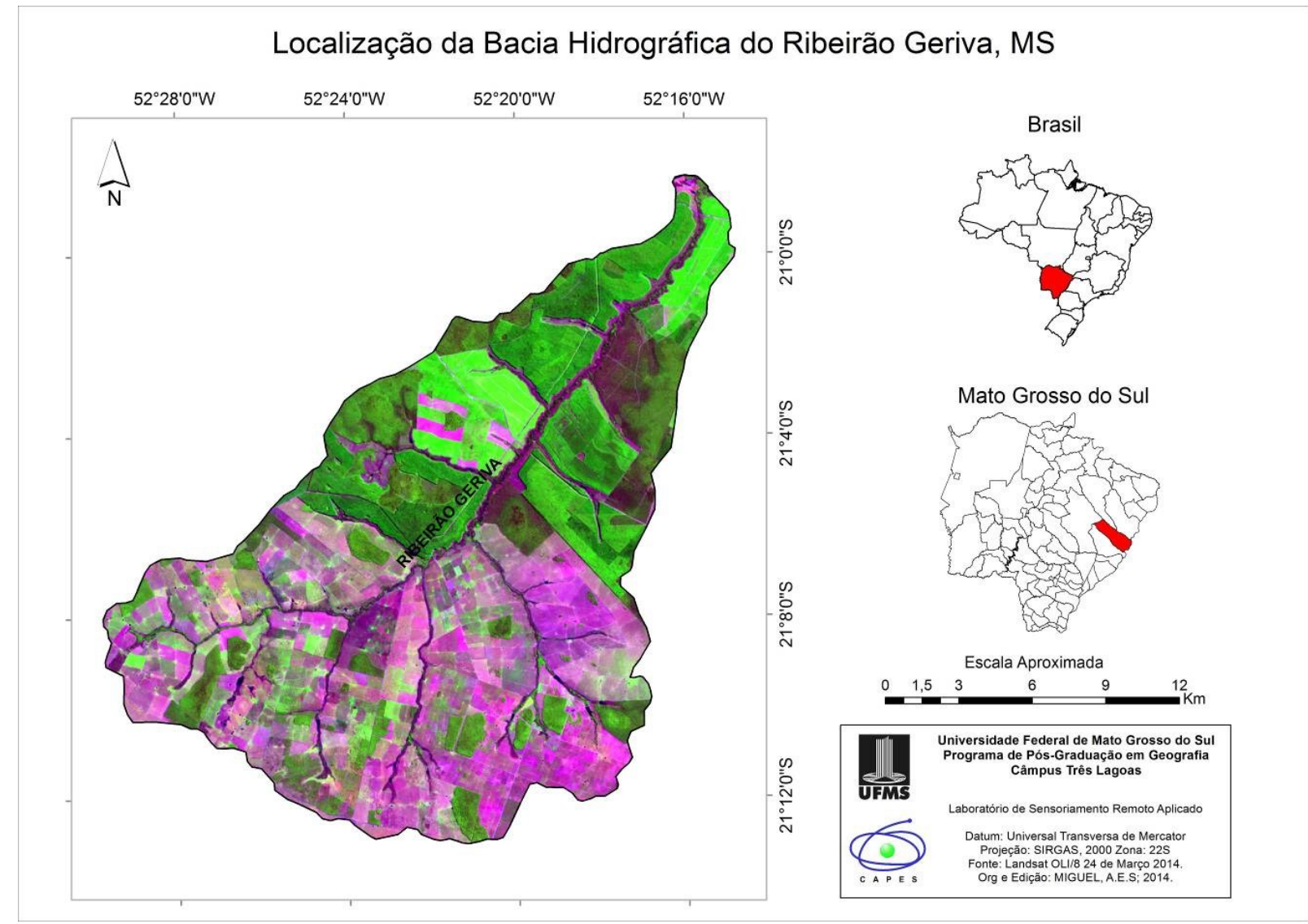

Fonte: USGS - United States Geological Survey.

\section{DESENVOLVIMENTO}




\subsection{METODOLOGIA}

A caracterização geológica da área de estudo foi elaborada com o auxílio do ArcGis $^{\circledR}$ 10, na extensão ArcMap 10, gerou-se o mapa geológico do estado do Mato Grosso do Sul na escala de 1:100.000 com os dados técnicos do SISLA. A partir dos dados recortou a área da bacia, calculando-se a área em $\mathrm{km}^{2}$ que cada disposição geológica ocupa na bacia.

A carta de solos da área de estudo foi elaborada com o auxílio do ArcGis ${ }^{\circledR} 10$, no mesmo procedimento descrito no parágrafo anterior, utilizando os dados técnicos do SISLA, que foram adicionados ao $\operatorname{ArcGis}^{\circledR}$, onde o mesmo descreve a disposição dos solos pelas siglas, onde foi nomeado de acordo com a nova nomenclatura da (EMBRAPA 2006) finalizando assim a carta de solos.

Para a caracterização da hierarquia fluvial da bacia foi utilizada a imagem SRTM, trabalhada no ArcGis $^{\circledR}$ 10. Após a delimitação da bacia, gerou automaticamente a hidrografia com o auxílio da ferramenta spatial analyst > hidrology. Após este procedimento, foram classificados os canais de $1^{a}$ ordem até $4^{a}$ ordem, sendo calculado o comprimento dos canais.

Para a elaboração da hipsometria, inicialmente utilizou-se a imagem SRTM, em seguida foi necessária a utilização de um MDT (Modelo Digital de Terreno) que foi gerado por triangulação irregular da grade (TIN) na ferramenta Tin Management > Create Tin, localizado 3D Analyst tools do ArcGis ${ }^{\circledR} 10$. Ainda com relação ao relevo da bacia, foi realizado o perfil longitudinal, sendo feito no percurso do rio principal da sua nascente até a foz.

Para a realização dos perfis transversais também foi utilizado o programa ArcGis 10, onde foram traçados perfis próximos ao alto curso, no médio curso e próximo à foz no baixo curso.

A declividade da bacia foi obtida através dos dados altimétricos da imagem SRTM, com o auxílio da ferramenta Spatial Analyst, em seguida a opção Surface e Slope, sendo que pode ser escolhido declive em graus e/ou porcentagem, neste caso foi escolhida a porcentagem. 
Para a elaboração do uso e ocupação da terra foi feita uma interpretação de imagens de satélite Landsat 8, bandas 4, 5 e 6 do mês de março de 2014 adquiridas gratuitamente no site do USGS - Serviço Geológico dos Estados Unidos.

\subsection{RESULTADOS}

Segundo os dados obtidos pelo Sistema Interativo de Suporte ao Licenciamento Ambiental (SISLA/IMASUL), a BHRG tem presença da Formação Caiuá, Formação Santo Anastácio e Depósitos Aluvionares, como mostram a Figura 2.

A Formação Caiuá na bacia foi constatada em uma área de aproximadamente 13,69 km², sendo que obtêm uma característica uniformemente litológica, que se observa tanto no oeste paulista como no norte paranaense, com espessura não superior a $150 \mathrm{~m}$, é representada por arenitos bastante porosos, facilmente desagregáveis, e na maioria das vezes seus grãos encontram-se envoltos por uma película de limonita (SEPLAN, 1990).

Já a Formação Santo Anastácio foi predominante da área, com um total de $345,01 \mathrm{~km}^{2}$ e tem como característica o arenito cinza-pardo, vermelho-arroxeado ou creme em sua parte inferior, encontrando-se sempre envolto por uma película limonitizada. Em sua camada superior apresenta arenito fino a médio, com predominância de terrenos arenosos em detrimento de constituintes pelíticos de coloração marrom-avermelhado ou pardacento, de seleção média com cimento silicoso e carbonático mais freqüente (SEPLAN, 1990).

Os Depósitos Aluvionares compreenderam apenas áreas próximas à foz do ribeirão Geriva, sendo uma área plana onde este tipo de formação prevalece e abrangeu um total de $0,59 \mathrm{~km}^{2}$. Essa formação se constitui os aluviões antigos e recentes encontrados na forma de faixas estreitas e alongadas com altitudes baixas, encontrados ao longo das calhas dos principais rios (CETEC, 1999, p.17).

Figura 2: Geologia da Bacia Hidrográfica do Ribeirão Geriva, Brasilândia/MS. 


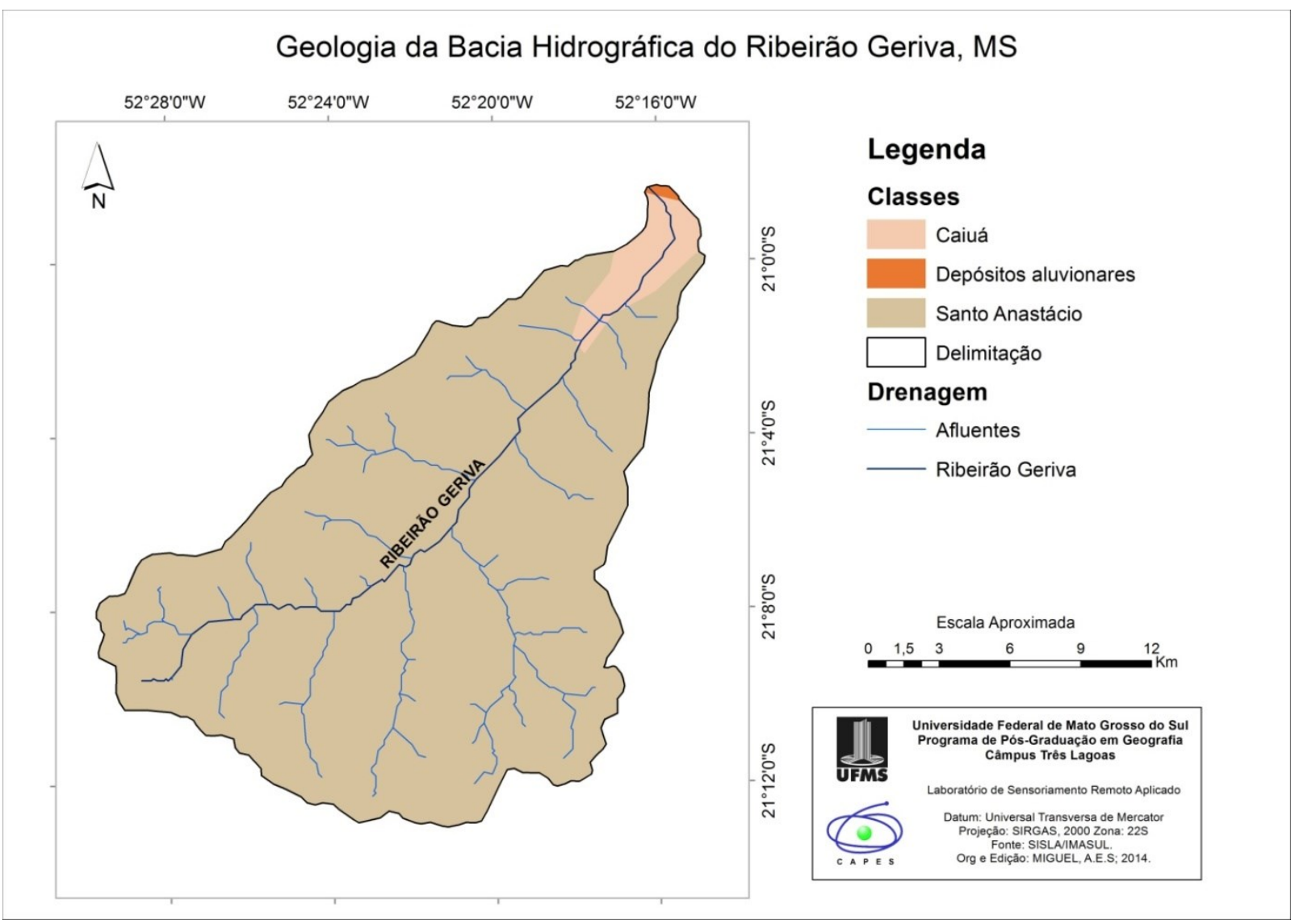

Fonte: SISLA/IMASUL.

A Formação Caiuá na bacia foi constatada em uma área de aproximadamente $13,69 \mathrm{~km}^{2}$, sendo que obtêm uma característica de espessura não superior a $150 \mathrm{~m}$, é representada por arenitos bastante porosos, facilmente desagregáveis, e na maioria das vezes seus grãos encontram-se envoltos por uma película de limonita (SEPLAN, 1990). Já a Formação Santo Anastácio foi predominante da área, com um total de $345,01 \mathrm{~km}^{2}$ e tem como característica o arenito cinza-pardo, vermelho-arroxeado ou creme em sua parte inferior, encontrando-se sempre envolto por uma película limonitizada (SEPLAN, 1990).

Os Depósitos Aluvionares compreenderam apenas áreas próximas à foz do ribeirão Geriva, sendo uma área plana onde este tipo de formação prevalece e abrangeu um total de $0,59 \mathrm{~km}^{2}$. Essa formação se constitui os aluviões antigos e recentes encontrados na forma de faixas estreitas e alongadas com altitudes baixas, encontrados ao longo das calhas dos principais rios (CETEC, 1999, p.17). 
Uma importante variável aliada à geologia, na busca pela análise integrada dos elementos físicos deste ambiente, é com relação aos solos da BHRG, onde é demonstrado na Figura 3.

Figura 3: Solos da Bacia Hidrográfica do Ribeirão Geriva, Brasilândia/MS.

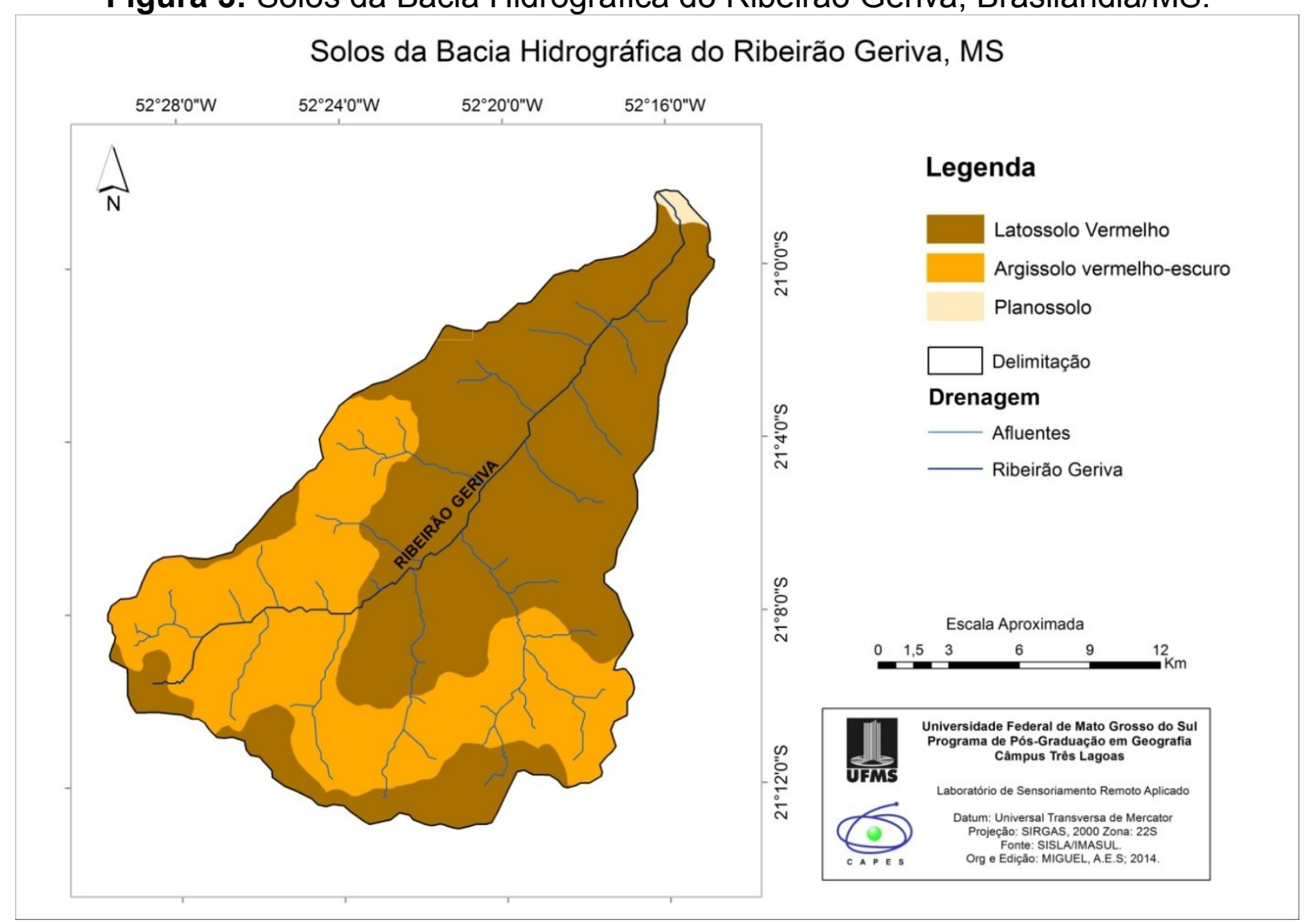

Fonte: SISLA/IMASUL.

Predominando o Latossolo Vermelho, com uma área de $214,17 \mathrm{~km}^{2}$, que são solos constituídos de material mineral, sendo solos em avançado estágio de intemperização, bem evoluídos, normalmente profundos e variam de fortemente a bem drenados. Sendo encontrados geralmente em regiões planas ou suaves onduladas (EMBRAPA, 2006).

O Argissolo Vermelho escuro são solos minerais, que tem como características diferenciais a presença do horizonte $B$ textural de argila de atividade baixa ou alta conjugada por bases baixa ou caráter alitico (EMBRAPA, 2006) e ocupa uma área de apenas $1,75 \mathrm{~km}^{2}$ na bacia. 
Os Planossolos presentes na bacia abrangem uma área de 143,37 km², são solos típicos de relevo plano e áreas rebaixadas, são solos minerais imperfeitamente ou mal drenados, com horizonte superficial ou subsuperficial aluvial de textura mais leve. (EMBRAPA, 2006).

Quando se busca uma análise integrada, todo e qualquer elemento de uma bacia hidrográfica deve ser analisado e também notado a influência deste sobre os demais elementos, dessa forma, a hierarquia fluvial, Figura 4 e Tabela 1, se torna outra importante análise dentro da proposta desta pesquisa.

Segundo Christofoletti (1980), a hierarquia fluvial consiste no processo de se estabelecer a classificação de determinado curso d'água (ou da área drenada que lhe pertence) no conjunto total da bacia hidrográfica na qual se encontra com a função de facilitar e tornar mais objetivos os estudos sobre as bacias hidrográficas.

Figura 4: Hierarquia Fluvial da Bacia Hidrográfica do Ribeirão Geriva, Brasilândia/MS.

Rede de Drenagem da Bacia Hidrográfica do Ribeirão Geriva, MS
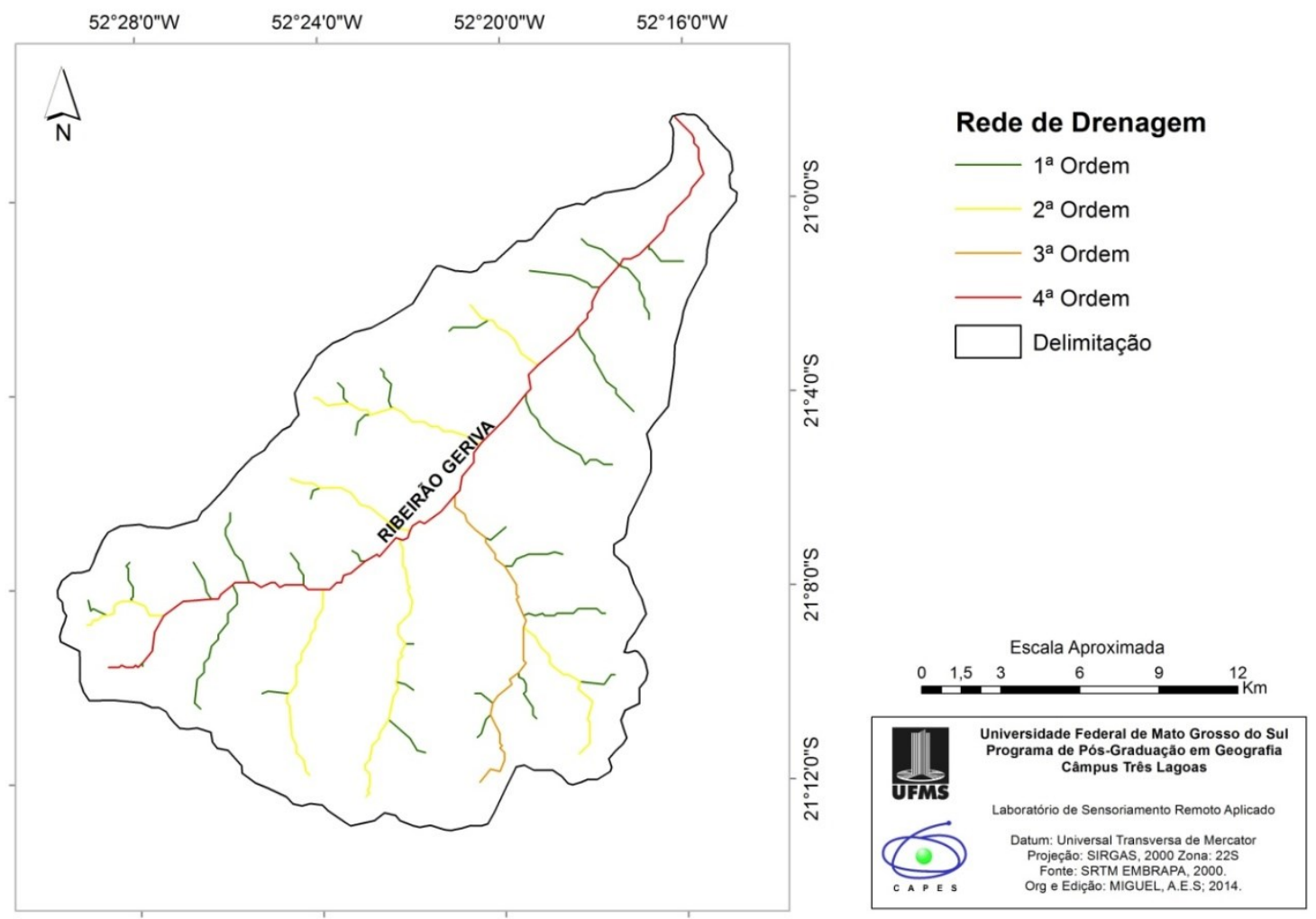

Fonte: SRTM, EMBRAPA, 2000. 
Tabela 1: Hierarquia Fluvial da Bacia Hidrográfica do Ribeirão Geriva

\begin{tabular}{c|c|c}
\hline Ordem i & Número de Segmentos & Comprimento Médio $\mathbf{( k m )}$ \\
\hline $1^{\circ}$ & 30 & 54,87 \\
\hline $2^{\circ}$ & 7 & 44,79 \\
\hline $3^{\circ}$ & 1 & 13,55 \\
\hline $4^{\circ}$ & 1 & 35,75 \\
\hline
\end{tabular}

Segundo a proposta de Horton (1945 apud CHIRSTOFOLLETI, 1980) a hierarquia fluvial da BHRG é de $4^{\mathrm{a}}$ ordem, com 30 afluentes de $1^{\mathrm{a}}$ ordem, 7 afluentes de $2^{\mathrm{a}}$ ordem, 1 afluente de $3^{\mathrm{a}}$ ordem, 1 afluentes de $4^{\mathrm{a}}$ ordem; a Tabela 4 apresenta índices métricos totais para cursos de cada ordem, sendo para os de $1^{\text {a }}$ ordem 54,87 km, $2^{\mathrm{a}}$ ordem $44,79 \mathrm{~km}, 3^{\mathrm{a}}$ ordem $13,55 \mathrm{~km}, 4^{\mathrm{a}}$ ordem $35,75 \mathrm{~km}$.

Juntamente com a hierarquia fluvial e os parâmetros apresentados, a carta hipsométrica, Figura 5 e os perfis longitudinal e transversais constituem dados onde a elevação foi dividida, demonstrando a área ocupada por cada intervalo de altitude.

Figura 5: Hipsometria e Perfis Topográficos da BHRG, Brasilândia/MS.

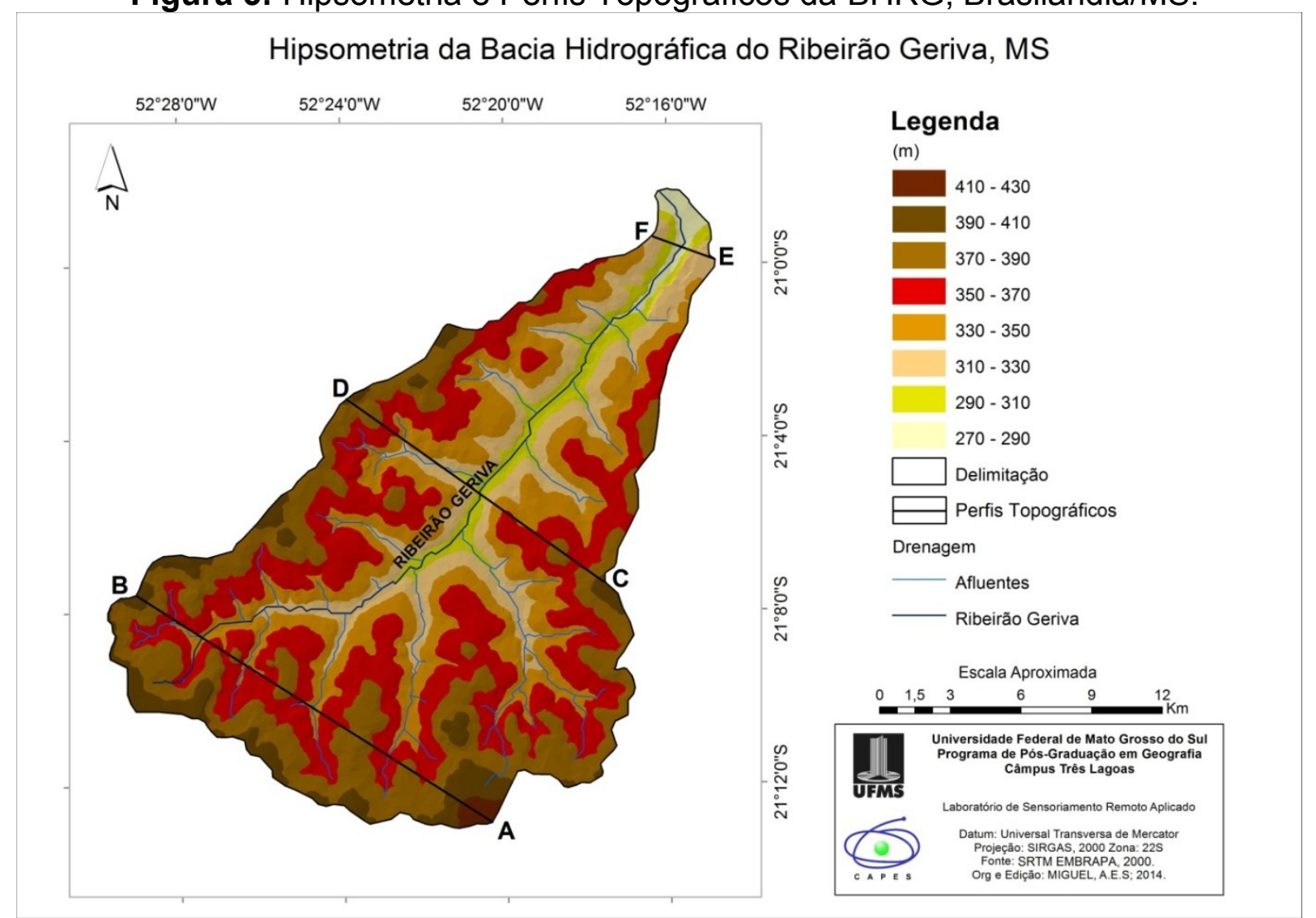

Fonte: SRTM, EMBRAPA, 2000. 
A hipsometria é outra importante variável na análise integrada dos elementos físicos da bacia, pois quanto o maior desnível da área, maior vai ser seu escoamento, alteranto de forma direta no solo, relevo, uso e ocupação e nos demias elementos presente em uma bacia hidrográfica.

A carta hipsométrica foi gerada a partir das curvas de nível, conforme a Figura 5, mostram que a maior altitude da bacia é de 412 metros e a menor altitude é de 284 metros. Para a compreensão das inclinações, desníveis e altitudes, foram elaborados alguns perfis topográficos, como: transversal do alto, médio e baixo curso, assim como o perfil longitudinal que foi elaborado da cota mais alta próximo à nascente até a foz do ribeirão Geriva.

O perfil longitudinal de um rio (Figura 6) é levantado a partir de uma linha que une pontos do seu leito, desde a nascente até a foz, e permite visualizar o declive do leito do rio ao longo do seu percurso. Além de entender melhor a dinâmica fluvial, pois mostra a sua declividade, ou gradiente, sendo a representação visual da relação entre a altimetria e o comprimento do curso d'água (CHRISTOFOLETTI, 1981).

Figura 6: Perfil Longitudinal da BHRG, Brasilândia/MS.

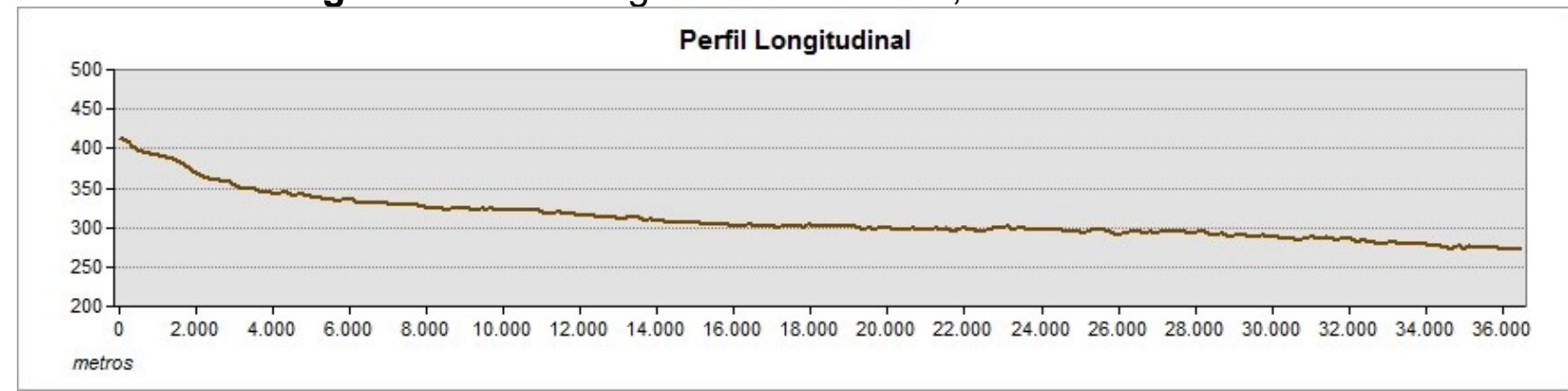

Fonte: SRTM, EMBRAPA, 2000.

Observou-se através do perfil longitudinal uma variação onde a cota mais alta apresentada é de 409 metros e 284 metros a menos elevada, mostrando um desnível de 125 metros, constatando um desnível médio de 3,42 m/km.

A Figura 7 representa o perfil transversal do alto curso da BHRG abrangendo uma distância de $6,85 \mathrm{~km}$. No ponto A tem uma elevação de $394,02 \mathrm{~m}$ e no ponto B tem uma elevação de 400,87 m. 
Figura 7: Perfil Transversal do Alto Curso da BHRG, Brasilândia/MS.

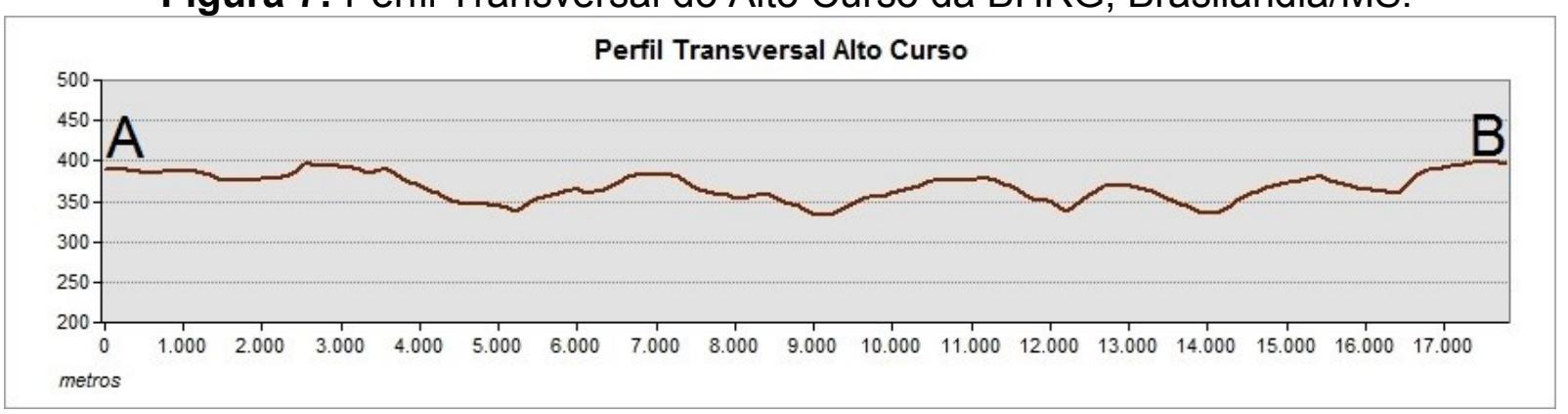

Fonte: SRTM, EMBRAPA, 2000.

A Figura 8 representa o perfil transversal traçado no médio curso da bacia do Ribeirão Geriva abrangendo uma distância de $13,44 \mathrm{~km}$. O ponto $\mathbf{C}$ tem uma elevação de $398,23 \mathrm{~m}$ e no ponto $\mathrm{D}$ tem uma elevação de $400,14 \mathrm{~m}$.

Figura 8: Perfil Transversal do Alto Curso da BHRG, Brasilândia/MS.

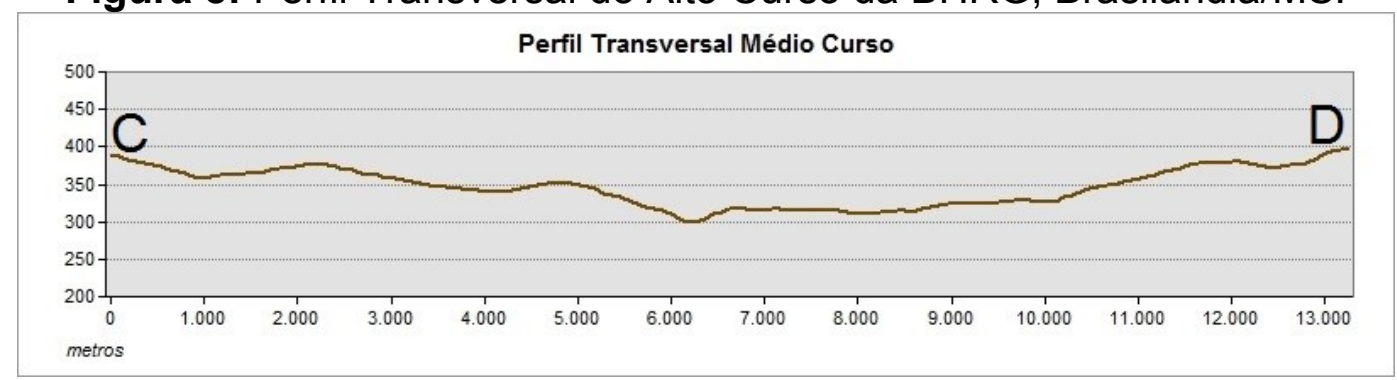

Fonte: SRTM, EMBRAPA, 2000.

A Figura 9 representa o perfil transversal traçado no baixo curso da BHRG abrangendo uma distância de 11,94 km. O ponto $\mathbf{E}$ tem uma elevação de 339,02 m e no ponto $\mathbf{F}$ tem uma elevação de $327,08 \mathrm{~m}$.

Figura 9: Perfil Transversal do Alto Curso da BHRG, Brasilândia/MS. 


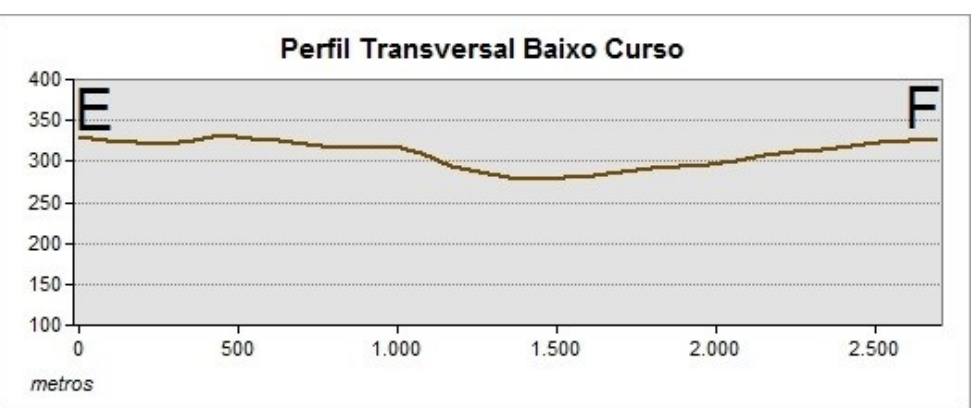

Fonte: SRTM, EMBRAPA, 2000.

Um fator que surge como uns dos principais na análise integrada todos os elementos físicos e as interações que caracterizam a BHRG é a declividade da bacia, uma vez que a mesma exerce influência direta sobre a quantidade de perda de solo por erosão, (OLIVEIRA et al., 2007), modificando assim os demais elementos.

Analisando a Figura 10 e comparando com os dados da Tabela 2, fica claro o predominio dos baixos graus de inclinação do terreno, (0 a 6\%) teve uma área de $338,21 \mathrm{~km}^{2}$ do total da bacia, sendo predominante um relevo plano sem muitas alterações bruscas de altitude. A segunda classe é de 6-12\% de declividade, abrangendo uma área relativamente pequena, apenas $20,57 \mathrm{~km}^{2}$.

A classe nomeada como média, de 12 a $20 \%$ de declive, se apresentou em apenas 0,51 km², que segundo Lepsch et al. (2002) são áreas com predomínio a problemas com erosão, entretanto, impróprias para culturas anuais e indicadas para culturas perenes. 
Figura 10: Declividade da Bacia Hidrográfica do Ribeirão Geriva, Brasilândia/MS.

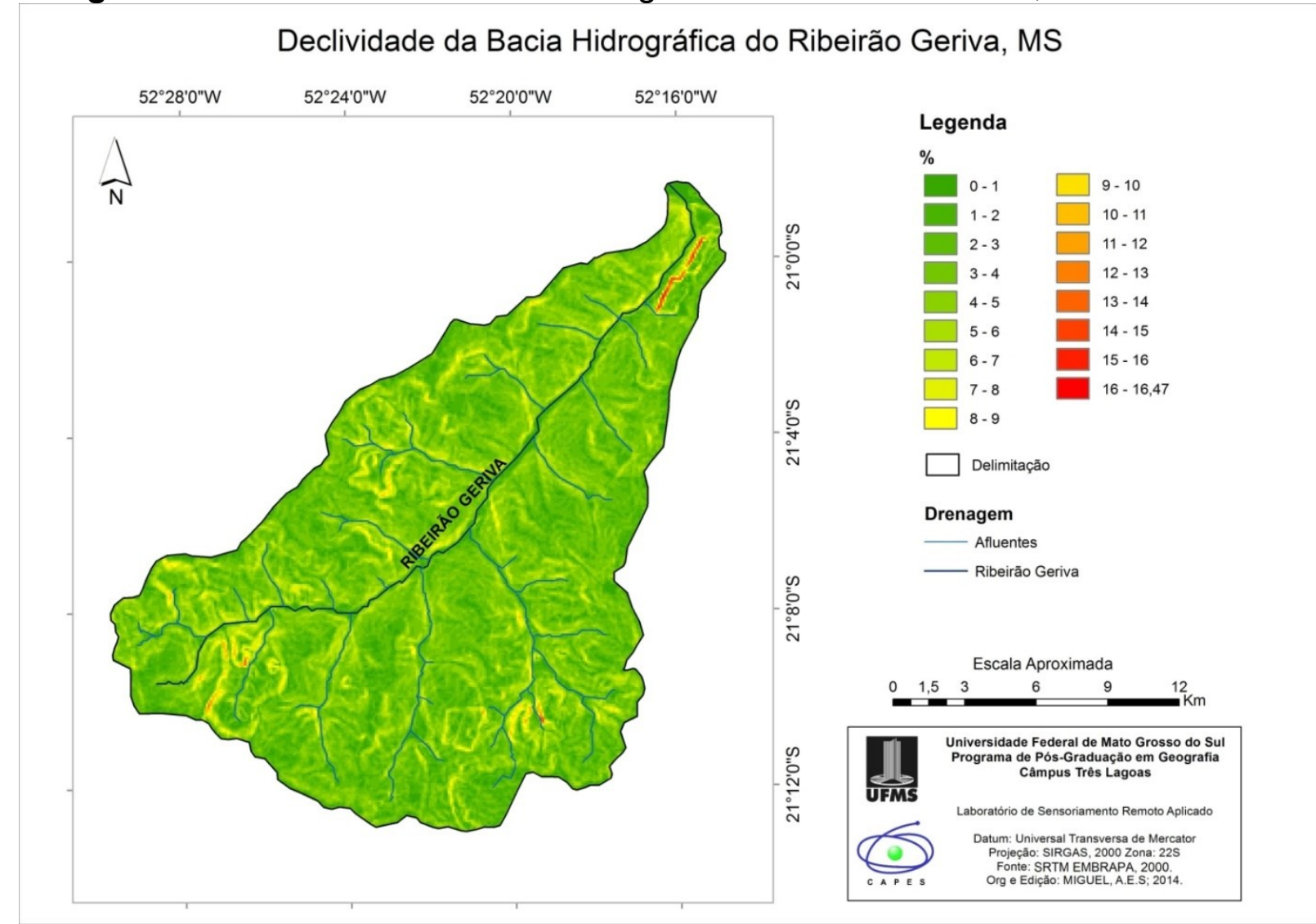

Fonte: SRTM, EMBRAPA, 2000.

Tabela 2: Declividade na bacia do ribeirão Geriva em área $\left(\mathrm{km}^{2}\right)$ e porcentagem (\%).

\begin{tabular}{c|c|c|c}
\hline Classes de Declive (\%) & Categorias Hierárquicas & Área $\left.\mathbf{( k m}^{2}\right)$ & Área (\%) \\
\hline 0 a 6 & Muito Fraca & 338,21 & 94,13 \\
\hline 6 a 12 & Fraca & 20,57 & 5,72 \\
\hline 12 a 20 & Média & 0,51 & 0,15 \\
\hline Total & & $\mathbf{3 5 9 , 2 9}$ & $\mathbf{1 0 0 , 0 0}$ \\
\hline \multicolumn{4}{|r}{}
\end{tabular}

Segundo Tucci e Clarke (1997), para minimizar qualquer tipo de impacto devido ao declive de determinado local, a cobertura vegetal possui um papel prático na absorção dos excessos hídricos.

Dessa forma, o uso e ocupação da terra é de extrema importância na proposta elaborada por esta pesquisa, no ano de 2014, Figura 11, é caracterizado pela presença de pastagens e também grande parte do cultivo de silvicultura que se encontra crescente na região devido a proximidade com a usina de celulose localizada ao norte, no municipio de Três Lagoas/MS. 
Figura 11: Uso e Ocupação da Terra na BHRG, Brasilândia/MS.

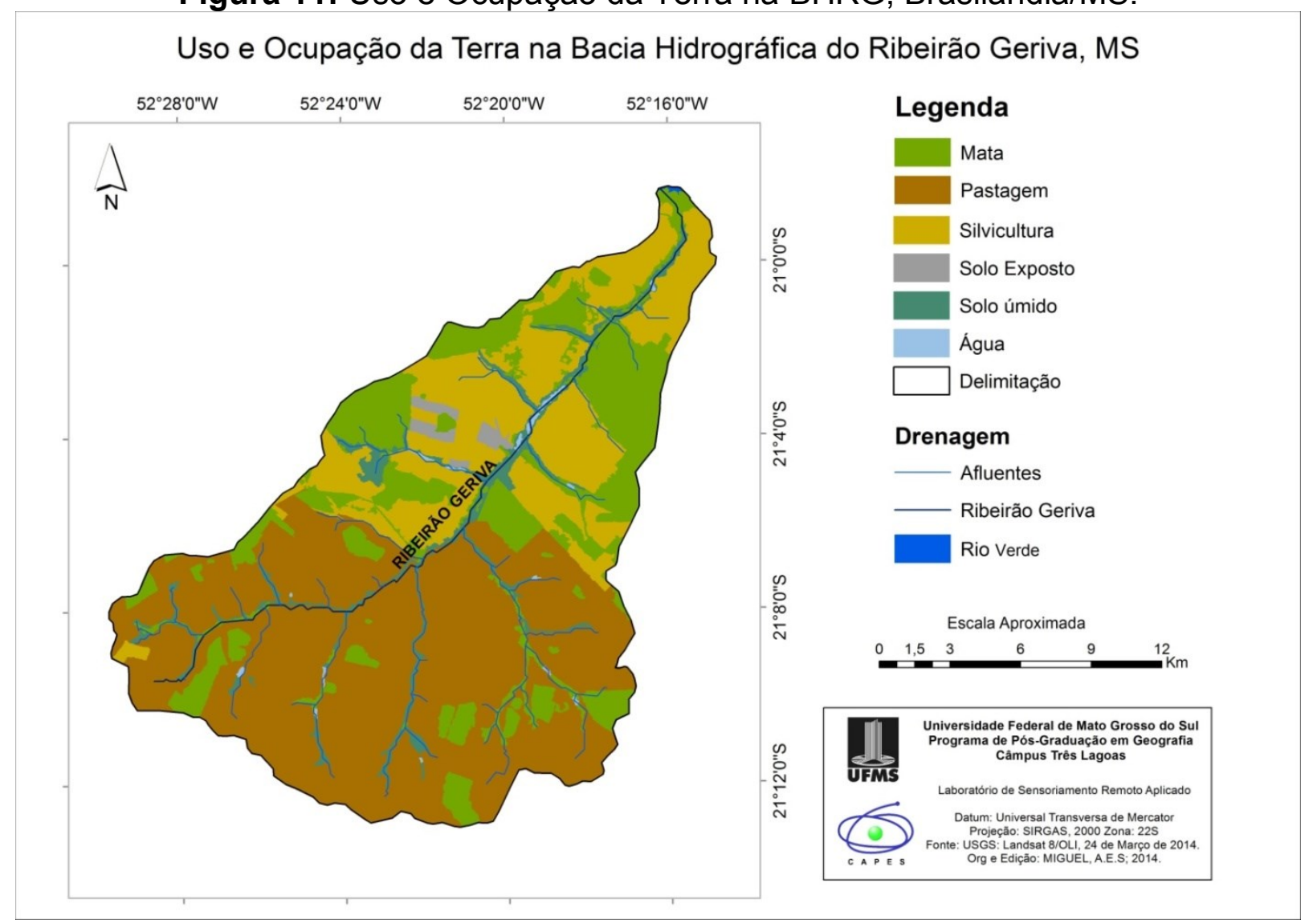

Fonte: USGS - United States Geological Survey.

$\mathrm{Na}$ Tabela 3 mostra os dados gerados pelo $\mathrm{ArcGis}^{\circledR}$, em $\left(\mathrm{km}^{2}\right)$ e porcentagens (\%) do uso e ocupação do solo no ano de 2014.

Tabela 3: Uso e Ocupação da Terra da BHRG, MS.

\begin{tabular}{c|c|c}
\hline Uso e Ocupação da Terra & Área $\mathbf{( k m}^{\mathbf{2}} \mathbf{)}$ & Área (\%) \\
\hline Água & 1,36 & 0,38 \\
\hline Mata & 78,43 & 21,82 \\
\hline Pastagem & 181,81 & 50,60 \\
\hline Silvicultura & 78,03 & 21,72 \\
\hline Solo Exposto & 3,01 & 0,84 \\
\hline Solo úmido & 16,65 & 4,64 \\
\hline
\end{tabular}

Analisando a Tabela 3 e comparando com a Figura 11, no mês de março de 2014, a classe de água representava uma área de $1,36 \mathrm{~km}^{2}$, sendo $0,38 \%$ do total da área. A classe mata representa uma área de 21,82\%. É visível o predomínio de pastagem na bacia do ribeirão Geriva, representando uma área de $181,81 \mathrm{~km}^{2}$ sendo $50,60 \%$ do total da área, sendo a maioria delas destinada a criação de gado de corte. 
A classe silvicultura representa uma área de $78,03 \mathrm{~km}^{2}$ sendo $21,72 \%$, está classe é representada pelo cultivo de eucalipto.

O Solo exposto foi representado por áreas sem cobertura vegetal sendo elas para preparação de terra para novo plantio ou até mesmo erosões e apresentou 3,01 $\mathrm{km}^{2}$ ou $0,84 \%$ do total da área da bacia. Já a classe Solo úmido que é representada por áreas de várzeas e áreas de alagamento e apresentou uma área de 16,65\%.

\section{CONCLUSÃO}

Foi constatado que estudos integrados de determinado ambiente pressupõem o entendimento de sua dinâmica, com ou sem interferência do homem. Dessa forma essas análises podem auxiliar em um futuro planejamento para a área, que tem grande parte de suas terras ocupadas pela ação antrópica (Silvicultura), onde se não ocorrer um manejo correto do solo, acaba alterando os recursos hídricos e o solo, que por sua vez alteram os demais elementos desta bacia hidrográfica e de outros ambientes próximos. Neste sentido, que a análise integrada é necessária, pois notase que todos os elementos do ambiente são interligados.

A BHRG predominam relevo suavemente aplainado, recobertos por latossolos vermelho, que são solos constituídos de material mineral, normalmente profundos encontrados em região planas como esta, que se assenta sobre terrenos do grupo Bauru, formação Santo Anastácio, onde sua camada superior apresenta arenito fino a médio, com predominância de terrenos arenosos.

Através dos mapas hipsométricos, perfis topográficos e declividade, notam-se apenas alguns desníveis mais acentuados, mas de forma geral, é uma área plana, com pouca variação de altitude, tanto é que na sua grande maioria foi constatada a classe de 0 a $6 \%$ de declividade, que são áreas com nenhuma ou somente pequenas limitações de uso, são indicadas para o plantio de culturas anuais, com o uso de práticas simples de conservação do solo.

Constata-se que a BHRG tem forte influência antrópica no uso e ocupação da terra, onde sua grande maioria foi de pastagens e sua economia é voltada pra pecuária, porém, como tem se tornado característico na região ocorreu em um grande 
aumento nas áreas de silvicultura, ocorrendo uma alteração na paisagem da bacia e consequentemente nas interações existentes nela.

Pode-se notar que todas estas variáveis são de extrema importância tanto para a análise integrada da paisagem e do ambiente, como também sobre a dinâmica que ocorre na BHRG, pois o relevo, solos, declividade, uso e ocupação da terra, são correlacionados, onde qualquer alteração em um destes elementos, acarreta uma mudança em todo o ambiente.

\section{REFERÊNCIAS}

CETEC. Centro Tecnológico de Fundação Paulista de Tecnologia e Educação. CBH-BT - Comitê da Bacia Hidrográfica do Baixo Tietê. Situação dos Recursos Hídricos do Baixo Tietê - UGRHI 19. Minuta Preliminar do Relatório Técnico Final. Diretor - CTEC: Wiltevar Verati. Lins, ago. 1999.

CHRISTOFOLETTI, A. Geomorfologia Fluvial. São Paulo: Edgard Blucher, 1981. 313p.

Geomorfologia. $2^{\mathrm{a}}$ edição. São Paulo: Edgard Blucher, 1980. 188p.

EMPRESA BRASILEIRA DE PESQUISA AGROPECUÁRIA - EMBRAPA. Centro Nacional de Pesquisa de Solos. Sistema brasileiro de classificação de solos. 2. ed. Rio de Janeiro, 2006. 306p.

IBGE. Instituto Brasileiro de Geografia e Estatística. Manual de uso e ocupação da terra. Manuais Técnicos em Geociências. Brasil número 7. Brasília, 2006. 91p.

LEPSCH, I. F. Formação e Conservação dos solos. São Paulo: Ofícina de Textos, 2002,178p.

OLIVEIRA, A. M. M; PINTO, S. A. F; LOMBARDI NETO, F. Caracterização de indicadores da erosão do solo em bacias hidrográficas com o suporte de geotecnologias e modelo predictivo. Estudos Geográficos, Rio Claro, v.5, p.63-86, 2007.

RAMALHO-FILHO, A; BEEK, K. J. Sistema de avaliação da aptidão agrícola das terras. 3. ed. Rio de Janeiro: EMBRAPA-CNPS, 1995. 65 p.

SANTANA, D. P. Manejo integrado de Bacias Hidrográficas. Sete Lagoas: Embrapa Milho e Sorgo, 2003. 63p.

SANTOS, M. A natureza do espaço: técnica e tempo, razão e emoção. São Paulo: Hucitec, 1996.

SEPLAN-MS - Secretaria de Planejamento de Mato Grosso do Sul. Atlas Multirreferencial do Estado de Mato Grosso do Sul. Campo Grande/MS, SEPLAN-MS, 1990. 28p.

SISLA/IMASUL - Sistema Interativo de Suporte ao Licenciamento Ambiental - Disponível em: <sisla.imasul.ms.gov.br> Acesso em: 20 de Maio. 2014.

TRICART, J. Ecodinâmica. Rio de Janeiro, IBGE/SUPREN. 1977. 91 p.

TUCCI, C. E. M.; CLARKE, R. T. Impacto das mudanças de cobertura vegetal no escoamento: Revisão. Revista Brasileira de Recursos Hídricos, v.2, n.1, p.135-152, 1997. 